\title{
Safe Socio-natural Evolution on the Back of Environmental Risks
}

\author{
Tatiana Naumova \\ Flight and Life Safety Department \\ Moscow State Technical University of Civil Aviation \\ 20 Kronshtadtskyblvd. \\ Moscow, Russian Federation 125993 \\ E-mail: naumova_0211@mail.ru
}

\begin{abstract}
Environmental safety is perceived as one of the priority needs of the personality, society and the state, among their other vital needs, since for the first time in the human history it is becoming a decisive factor for the self-preservation of mankind at the time of the global environmental crisis. Environmental safety is seen as a measure of environmental hazard, where the main properties of the social and economic system, as well as the vector of its progressive development are preserved. The quantitative certainty of the environmental hazard, which combines its probability and severity, is reflected by environmental risk. The possibility of resolving the contemporary global environmental conflict is discovered through analysis of environmental risks.
\end{abstract}

Keywords-global environmental conflict; sustainable development; socio-ecosystem; environmental safety; environmental risk

\section{INTRODUCTION}

The historic development of the human world has been accompanied by the growth of the number of people, increase of the production and consumption volumes. The evolutionary social processes were accompanied by the growing demand for natural resources and by accumulation of waste and pollution. At the cusp of 21 st century, for the first time in its history the humanity encountered the circumstance of an unprecedented nature and scale: the challenge of surviving in the nature that had been transformed by it. As people functioned, the critical situation emerged as a consequence of the historical paradigm of interaction between the society and the nature centered around the idea of humans' consumerist attitude to the environment based on the discourse about domination of man as an agent. Mankind has succeeded in transgressing the boundaries of the biosphere, which resulted in fundamentally new conditions for development of the global ecosystem, where anthropoid-social processes are beginning to prevail over the physical, chemical and biological ones. Whereas the economic activity of the pre-industrial era was accompanied by local disruption, the three centuries of modernization, rapid industrial and technological growth have extrapolated the scale of the problem to the regional level, and later on to the global one: "... the global environmental crisis which is so much spoken about today emerged naturally as an inadvertent result of the human economic activity and the influence of its exponential growth on the external natural environment" [1]. As a result, gradually a contradiction has ripened between the growing material needs of the society and the nature's ability to satisfy the same. This contradiction is of universal nature, it concerns every individual and the humanity as a whole, and, therefore, in scientific and popular nature it is defined as a fundamental environmental conflict. The scenarios of its resolution determine the trends of further dynamics of the condition of the global social system and its environment: whether the contemporary civilization will develop along the progressive path, or whether it will slip into a global environmental disaster.

\section{Change OF THE SCIENTIFIC SAFETy PARAdigM}

Safety has always been and still remains one of the main human needs, therefore, the interest to its various aspects has been growing for several decades already. The ecology issue demonstrates the global nature and scale of contemporary threats and hazards. It is becoming obvious that without extensive use of new methods and mechanisms aimed at ensuring the civilization's safety it will be impossible to recover from the general civilization crisis.

Since the middle of the previous century the scientific circles have been revising the principles of securing safety. The concept of absolute safety, which did not deny the presence of natural, anthropogenic, military and other threats, however, implied that only technical miscalculations and errors in organizing the protection of the society from such threats result in real events, and allowed for availability of solutions that will ensure full safety, was replaced by a new paradigm of relative safety, according to which danger accompanies any activities, any natural and anthropogenic process, and that the absolute safety level is unattainable. The new concept primarily required quantification of the danger level degree. The science and culture began using risk indicators as a quantitative degree of danger, the form of its estimation determined by probability. The relative safety concept was now called the relative risk concept.

Undoubtedly, scientific and technical progress mitigates the share of traditional risks. However, the share of the risks, 
which are caused by the globalization process and generated by the transition from industrialism to post-industrialism, is growing. Therefore, changes occur in the public awareness, which determines the assessment and perception of particular social positions, norms, rules and valuables that shape social behavior, and, therefore, the understanding, perception and evaluation of risks is changing. Being a dynamically developing system, the society, on the one hand, is a source, and on the other is a victim of the increasing number of the emerging threats and challenges. The risk agenda virtually affects all spheres of the society's life: economy, sociology, jurisprudence, psychology, natural and technical sciences. Risk is a complicated and controversial social phenomenon, whose nature is affected not only by technological, economic, political, but also by socio-cultural factors. Risk is becoming an attribute of social life. Operation in risky conditions sets the task before the community to foresee the possible future options by choosing between alternative solutions, minimizing risks and adapting to new risky conditions of the existence. Risk is an interdisciplinary concept, which constitutes the basis of the contemporary philosophical safety narrative.

\section{ENVIRONMENTAL SAFETY FROM THE PERSPECTIVE OF THE SOCIO-NATURAL SYSTEMIC UNITY}

In terms of systemic thinking, socio-natural components make up the same system. V. F. Protasov and A. V. Molchanov define the "society - natural environment" system as a totality of natural conditions, habitat and human production activity [2]. In order to designate the totality of natural and social components of different levels, the researchers of various aspects of the environmental agenda use different terms: anthropo-biogeocenosis, anthropogeocenosis, anthroposystem, anthropoecosystem, sicio-biosystem, socio-technoecosystem, socio-ecosystem, ecosphere, etc. In our point of view, the concept of socioecosystem is the most acceptable one.

The structure of the socio-ecosystem may be represented as interaction of two subsystems. One subsystem, the socioeconomic one, consists of social components that ensure the functioning of the society. It includes information and communication networks, production and industrial complexes and demographic processes. Another subsystem, the one of natural resources, is formed by components of the environment that are included into such life sustenance [3].

In the opinion of E. V. Girusov, such term as "socioecosystem" implies the application to the society of the laws of part-to-whole relationship, where the biosphere is the whole with regards to the society, and, therefore, the society should acquire a functional dependence with respect to the biosphere part whereof it forms, accept the laws of the biosphere, become an indispensable part thereof [4].

The understanding of the "society-nature" system as a socio-ecosystem includes the following matter of principle: environmental interactions within the socio-ecosystem do not constitute some specific type of interaction within the system like physical, chemical or biological interaction, but they are seen as some integrative type instead, not only with material energy, but also with information flows [5]. The relations between the subsystems are variable, according to the feedback principle. Human activity that transforms the environment is a systemically important basis, due to the fact that it connects the said components. The disruption of the smooth functioning of the environment, primarily, the biosphere, which regulates the condition of the entire global system, serves as the ontological basis for the evolution of the conflict in the socio-ecosystem.

Environmental safety is considered as preservation of the quality of the environment that is necessary for mankind to function subject to keeping the anthropogenic loads within the limits of the biosphere's bearing capacity. The ontological essence of the environmental safety as a prerequisite for the existence of the society, its stability and sustainability is supplemented by value-based, axiological content, which consists in preservation of favorable conditions for human activities. Benign environment, in turn, ensures non-threatening conditions for human life, preservation of health and development opportunities.

\section{RISK-GENERATING TENDENCIES OF SOCIO-NATURAL DYNAMICS}

During the last decade of the previous century, the focus in addressing environmental issues shifted towards attempts to combine the attributes of anthropocentric and biospherecentric outlooks, the ideas of global evolutionism with environmental rationality within the same development strategy. At the conference of the United Nations on environment and development(in Rio-de-Janeiro, Brazil, 1992), the strategy of civilization's sustainable development was proclaimed as the global activity program. The commitment to the new strategy was confirmed in the final documents of all the subsequent global environmental summits (Johannesburg, 2002; Rio-de-Janeiro, 2012). Sustainable development is understood as controlled social development balanced with natural biosphere processes. Sustainable development means such method of selforganization of the global socio-natural system, where its economic, social and environmental indicators remain within acceptable, or, better say, optimal limits. Economic development, social justice and environmental stability are becoming the conceptual provisions of the new strategy. The very idea of the sustainable development stems from the provision as per possibility of making development manageable, imparting the planned dynamics and direction to social changes.

The global measures undertaken within the context of sustainable development had allowed to achieve certain progress by year 2015. The attempts to curb the poverty growth rates were successful: despite the population growth by 2 billion people, more than 1 billion people managed to escape extreme poverty. More than 2.1 billion people improved their sanitary and household living conditions, more than 2.5 billion people gained access to sources of good quality potable water. The mortality among children up to the age of 5 was halved, HIV, malaria, tuberculosis transmission rates were suspended [6] [7]. The results of the broad-scale international socio-economic study "The 
Changing Wealth of Nations 2018: Building a Sustainable Future" published in 2018 showed that over the period of development of the global economic system from 1990 to 2015 , the welfare level had grown by approximately $66 \%$ worldwide [8].

At the same time, numerous studies of the socioecosystem dynamics that have gained popularity in recent decades and that have expanded the boundaries of understanding of the effect of the human activity on the planet evidence that the dialectic environmental conflict is further exacerbating. It has recently taken the inhabitants of the Earth only 40 years to double their numbers. The consumption of water, food, energy is growing even faster, which testifies to the higher consumption standards. Negative trends are supported by the global environmental indicators of the planet's condition.

Over the elapsed quarter of a century, the area of the forests on the planet has decreased by 2 million square meters, whereas a billion of people depend on the forests for their livelihoods [9]. Forest ecosystems contribute to preservation of the biosphere's biodiversity, maintaining the quality of the atmospheric air, climate formation.

According to the data of the International Union for Conservation of Nature and Natural Resources, about a quarter of mammal species worldwide are endangered. For the purposes of reflecting the results of the monitoring of the biodiversity status, some authoritative international studies use the Living Planet Index, which shows the condition of biosphere diversity and which is calculated on the basis of the collected data on populations of the species and averaged dynamics of their numbers. According to the "Living Planet Report 2016. Risk and resilience in a new era", which was prepared by the World Wildlife Fund, the indicators of the Living Planet Index evidence that during the period from 1970 to 2012, the numbers of the populations of the land species had declined by $38 \%$; the populations marine species shrank by $36 \%$; fresh water species - by $81 \%$. In general, the counts of populations of vertebrates in the biosphere have declined by $58 \%$, the decline rates average about $2 \%$ per year, while there are no signs of such process slowing down so far [10].

Such indicator of socio-natural disproportion as the ecological footprint is quite illustrative. Calculated in conventional units - global hectares (gha), it means the area of the biologically productive territory and water area (forests, plowing land, pastures, fishing trade areas), which are necessary for the production of the resources that are being consumed by us and for absorption and processing of our wastes. This differentiates it from bio-capacity - the actual biologically productive area involved in population sustainment. The ecological footprint demonstrates the rates of consumption of the planet's natural capital. The excess of its biological capacity means environmental deficit. Globally, this deficit arose in 1970, and later on it only got worse: in 2000 the ecological footprint exceeded the biological capacity by $27 \%$, in 2013 - by $40 \%$. According to the data as of 2017, the deficit had already reached 50\% [11]. This means that the rates of consumption of renewable resources exceed the speed of reproduction thereof by the factor of one and a half.

The specialists explain the global climate change primarily by anthropogenic emissions of carbon dioxide, whose dynamics are illustrated by the carbon component of the ecological footprint, the so-called carbon footprint. Over the last half a century the human carbon footprint has soared by the factor of 11, having passed the acceptable threshold as early as in the 60's of the previous century. Half of the total growth of carbon dioxide in the atmosphere since the preindustrial era has occurred over the recent 30 years [12] [13].

The data provided evidence that the nature of the dynamics of the global socio-ecosystem still remains paradoxical, unstable. No effective mechanisms of management of the sustainable development of the socionatural mega-system have been generated yet.

\section{ENVIRONMENTAL RisK AS THE MEASURE OF ENVIRONMENTAL HAZARD}

Like any other system, the socio-ecosystem tends to develop and seek to preserve itself. In the course of the system's functioning, these properties are interconnected subject to numerous criteria, and interact in a contradictory manner. On the one hand, the system seeks to preserve its essence and self-identity, on the other it tends to develop, and therefore undergoes inevitable change. It is the change of the system's quality as its integral overall attribute that evidences the advent and the results of the development process. The environmental hazard concept, which determines the possibility of full or partial loss of properties, the lower level of the quality of the system at hand, may serve as the differential specific attribute of the socioeconomic system. This property of the system is connected with the realization of self-preservation processes. A. I. Muravykh interprets the environmental hazard of the global socio-ecosystem as the possibility of realization of the regressive line of system change from higher organizational forms thereof to lower ones [14].

Since the modern safety theory postulates nonattainability of complete absence of danger, we can only talk about a particular hazard level. The problem of detection of the environmental hazard condition within such coordinates as "possibility-reality" needs to be supported by quantitative certainty.

For the purposes of quantification of possibility, the science has developed the concept of probability. In specific segments of the scientific knowledge, several probability concepts were developed: classic, frequency-based, logical, mathematical, etc. On the basis of narrow scientific views on probability, the philosophical probability concept is being presently formed. Probability is a quantified possibility measure. Probability characterizes the limits, within which possibility exists; it determines the degree of proximity of the possibility to realization, to reality. Probability points to the value of the possibility basis in reality. The term "probability" as an objective possibility and the degree of feasibility of the risk event is basic to the probabilities theory, 
creating the platform for comparison of events in terms of degree of their realization. A certain number, which is the higher the more probable the event is, serves as the event probability. The occurring event is deemed to be the most probable one, and, therefore, "probability" is closely related to the event frequency concept. In order to determine the degree of proximity of the possibility to reality, the probability scale from 0 to 1 is used (or, as percentage - up to $100 \%$ ). The boundaries of the probability scale, i. e., points 0 and 1 , are the moments, upon achievement whereof the possibility ceases to be the same, turning in one case into a non-possibility and in the other into reality. It should be noted that it is not always possible to express the possibility or probability in numerical terms with absolute precision. In such cases such assessments as "small probability", "large probability", "equiprobable" are used. Not every possibility is necessarily realized, but any possibility contains a certain degree of necessity and, consequently, a certain chance to become a reality. Probability is a degree of the necessary in the possible. Possibility, therefore, has a higher probability of realization. The use of such category as "probability" imparts a more specific, applied meaning to the "possibility" category raising its educational and practical importance [15].

Hazards may manifest themselves with a different degree of severity. The same hazard may result both in minor and in fatal consequences. Therefore, in order to make managerial decisions, the hazard quantification must provide the understanding of severity or, as some sources put it, the seriousness of the consequences. The risk degree is used as the value that combines the probability of realization and the severity of the hazard consequences [16].

In terms of quantity, the environmental hazard may be expressed via the environmental risk value. If the environmental risk exceeds the acceptable values, environmental hazard emerges. In this meaning environmental safety is such measure of environmental hazard that determines the interval of quantitative changes, within limits whereof the main properties of the socioecosystem are preserved, as well as the vector of its progressive development Environmental safety as mankind's urgent need is realized via the safety of the socio-ecosystem - its self-organization in the sustainable development context. Therefore, the possibility of resolution of the global environmental conflict is opened through reflection on environmental risks.

\section{CONCLUSION}

The theoretical and methodological insight into the essence of interaction between man and nature in Russian and international literature has been analyzed with sufficient thoroughness. The concept of sustainable development in the present version identifies the general principles of the humanity's socio-economic progress within biosphere's potential. The global community has accumulated a certain experience in the sphere of environmental management, with a breakthrough looming large in the understanding of the need to juxtapose losses and acquisitions resulting from such management. At the same time, the socio-natural dynamics' indicators evidence the continuing growth of the global environmental crisis. Since anthropogenic activity is endowed with the systemically important function in the global socio-ecosystem, not only does the environmental risk allow to judge about the condition of the environmental hazard in the mega-system, but also to provide landmarks for management and transformation activities of the society with regard to the environment within the global system and, therefore, to influence its development. The role of the environmental risk in the social evolution may be defined as the regulator of global environmental safety via controlled development of the socio-ecosystem. We will point out to an important innovation: safety and development are not pitted against each other, comprising a dialectic unity instead, while safety is considered not as a factor accompanying the activity's development, but as a factor that is inherent in it.

\section{REFERENCES}

[1] Veber A. B. Will the humans response to the ecological challenge? Age of Globalization, 2011,No.1,pp.110-121.

[2] Protasov V.F., Molchanov A.V. "Ecology, health and nature management in Russia," Ed. by V.F.Protasova. Moscow: Finance and Statistics, 1995,p. 32. (in Russian)

[3] Garanina O.D., Naumova T.V. Environmental safety: some aspects of the concept conceptualization. Scientific Bulletin of the Moscow State Technical University of Civil Aviation, 2014, No.209,pp.7277.(in Russian)

[4] Ecology and economics of nature management, A text-book for Higher educational institutions. Ed. by Professor Girusov E.V., Professor Lopatin V.N. 2d ed., rev. and added. Moscow: UNITYDANA, 2002, p. 13.(in Russian)

[5] Sosunova I.A. Methodology and methods of modern social ecology. Moscow: IIEPU, 2010, pp.52-53. (in Russian)

[6] UNDP. 2017.HumanDevelopmentReport 2016.HumanDevelopmentforEveryone[electronic resource].UnitedNations Development Programme,Available at:http://hdr.undp.org/sites/default/files/2016_human_development_re port.pdf(accessed:27.04.2018).

[7] TheMillennium Development Goals Report 2015[electronic resource] Available http://www.undp.org/content/dam/undp/library/MDG/english/UNDP MDG_Report_2015.pdf (accessed: 7.04.2018).

[8] LangeGlenn-Marie, WodonQuentin, CareyKevin. The Changing Wealth of Nations 2018: Building a Sustainable Future. Washington, DC: World Bank, 2018, pp. 5-6.

[9] The World Bank [electronic resource]. Available at: http://www.worldbank.org/(accessed: 17.04.2018).

[10] WWF. 2016. Living Planet Report 2016. Risk and resilience in a new era [electronic resource]. WWF International, Gland, Switzerland. Available https://www.footprintnetwork.org/content/documents/2016_Living_P lanet_Report_Lo.pdf(accessed: 17.04.2018).

[11] Global Footprint Network [electronic resource]. Available at: https://www.footprintnetwork.org/our-work/(accessed: 19.04.2018).

[12] Global Environment Outlook: Environment for the future we want (GEO-5) [electronic resource]. Available at: http://drustage.unep.org/geo/sites/unep.org.geo/files/documents/geo5 _report_full_en_0.pdf (accessed: 25.04.2018).

[13] UNEP. 2017. The Emissions Gap Report 2017 [electronic resource]. United Nations Environment Programme (UNEP), Nairobi. Available at: https://wedocs.unep.org/bitstream/handle/20.500.11822/22070/EGR_ 2017.pdf?sequence=1\&isAllowed=y(accessed: 25.04 .2018 )

[14] Muravikh A.I. Theoretical bases of ecological safety management.Moscow: KOMEK, 2008, p. 294. (in Russian) 
[15] Naumova T.V. The methodological significance of philosophical categories in the explanation of the essence risk. Scientific Bulletin of the Moscow State Technical University of Civil Aviation, 2012, No.182,pp. 52-57.

[16] Naumova T. V. Problematic aspects of the study of risks in the activities of the subject for the transformation of nature. Siberian Journal of Life Sciences and Agriculture,2014. No. 5.2, pp.740-748. 